\title{
REFLEXÕES ACERCA DO PAPEL DA RE-SIGNIFICAÇÃO DO \\ CORPO PELA EDUCAÇÃO FÍSICA ESCOLAR, FACE AO \\ ESTEREÓTIPO DE CORPO IDEAL CONSTRUÍDO NA \\ CONTEMPORANEIDADE
}

\section{REFLECTIONS ON THE ROLE OF REDEFINING THE BODY \\ THROUGH PHYSICAL EDUCATION AT SCHOOL, IN FACE OF THE IDEAL BODY STEREOTYPE CONSTRUCTED IN CONTEMPORARY SOCIETY}

Dr. Aldo Antonio de Azevedo

Esp. Andréia Santos Gonçalves

Universidade de Brasília/UnB

\section{Resumo}

O presente artigo, de cunho interpretativo, apresenta uma reflexão acerca do papel da Educação Física Escolar na re-significação do corpo, face ao estereótipo construído na contemporaneidade. Recorre-se, às contribuições de alguns estudiosos do corpo, em especial, Le Breton; de algumas idéias de sociólogos como Durkheim e Foucault e do antropólogo Mauss. Aborda-se, também, reflexivamente a questão do corpo, no "fazer" Educação Física, onde o professor e os alunos reúnem possibilidades de re-significação do corpo pela conscientização, superando a fragmentação e propondo a interdisciplinaridade na sua constituição. A reflexão exige, portanto, o reconhecimento da realidade da prática pedagógica da Educação Física na escola, enquanto espaço social emancipatório e não apenas mero reprodutor de práticas a-críticas.

Palavras-Chave: Corpo; Contemporaneidade; Re-significação; Mídia; Educação Física Escolar.

\section{Aproximando a Temática}

Nos últimos anos as discussões e os debates sobre a relação corpo-homemsociedade tornaram-se primordiais para àqueles que de alguma forma lidam com o corpo em diversos espaços sociais, dentre os quais a escola.

Considerado por Breton como fenômeno social, cultural e biológico, eixo de ligação do homem com o mundo, fundamento da existência individual e coletiva; o corpo, nos dias atuais, vem se constituindo como um objeto obscuro, ambíguo e confuso, em razão do discurso da modernidade, que prima pela apologia do corpo como um objeto, apoiado numa materialidade física, que incorpora em si a forma de mercadoria (BRETON, 2006, p. 9). 
Neste sentido, a corporeidade, segundo o autor supracitado, é socialmente moldável, ainda que seja vivida de acordo com o estilo particular do individuo. Desse modo, os outros indivíduos contribuem para modular os contornos de seu universo e dar ao corpo o relevo social que necessita.

O corpo torna-se, então, um produto, um rascunho a ser corrigido, um acessório da presença, testemunha de defesa usual daquele que o encarna, sendo, assim, a discrição da pessoa deduzida da feição do rosto ou das formas de seu corpo. (BRETON, 2006, p. 9).

Dentre as conseqüências imediatas dessa condição, tem-se percebido um grande apelo, efervescência e idolatria à imagem narcísea do corpo, que se traduz social e culturalmente nas instituições e nos discursos que nelas são produzidos. A escola, enquanto instituição social, não está imune a tais concepções, incorporando práticas que suscitam a crítica com fundo ideológico e pela dominação, que contribuem para sedimentar a visão do corpo como uma superfície de inscrição de eventos, práticas e relações de poder, sem apontar perspectivas distintas da simples crítica pela crítica, capazes de mostrar novos caminhos de re-significação do corpo nos espaços sociais.

A Educação Física constitui não apenas uma prática pedagógica onde professor e aluno se relacionam num espaço dinâmico; mas em uma área do conhecimento presente na grade curricular da escola, onde o corpo como seu objeto de intervenção, é o principal referencial a ser considerado no trabalho do professor e na ação do aluno. Desse modo, a Educação Física deveria servir para formar criticamente o sujeito (aluno) em seu processo de aprendizado, de conscientização e de aquisição de conhecimentos e experiências para a vida, respeitando as diferenças, o próprio corpo e o corpo do outro.

Daólio (2005), por exemplo, um dos estudiosos da Educação Física, considera que os alunos, independente de suas diferenças, são iguais quanto ao direito à prática de atividades físicas, pois a valorização excessiva do rendimento corporal nas aulas privilegia apenas um grupo de alunos que possuem melhores aptidões físicas, incentivando a competição e a formação de elites, nas aulas, de forma desnecessária, e 
o papel pedagógico da Educação Física deve visar à libertação integral do ser humano e à recuperação de sua dignidade corporal, buscando a autonomia de movimentos. ${ }^{1}$

A essência desse posicionamento e de outros que apontam críticas e denunciam o que está sendo feito, constantemente vêm à tona e leva-nos a refletir e a repensar o corpo na Educação Física, em especial, no que se refere à prática escolar. Desse modo, justifica-se no presente artigo a tentativa de apresentar condições e possibilidades para uma re-significação do corpo, avançando da concepção de objeto para a de sujeito.

Então a prática da Educação Física na escola hoje confere significados contemporâneos ao corpo? Que significados podem ser identificados nessa prática? Tais significados estão permeados pelos valores da concepção de objeto ou de sujeito? A considerar que a prática está permeada pela significação do corpo como objeto, a serviço da sujeição, das regras institucionais, do poder e da mídia, quais as condições de possibilidade de construir um novo significado desse corpo pela prática da Educação Física?

São questões como estas, que se pretende discutir, com a certeza de que o problema aqui não se esgota; mas, com a intenção de reacender os discursos nas práticas da Educação Física na escola. Afinal, não existe um discurso e uma prática, mas discursos e práticas que os indivíduos constroem nas instituições.

O corpo, então, é hoje um desafio sócio-politico-economico importante e diante deste cenário redescobri-lo escreve um movimento que permite re-significá-lo como um potente marcador social da contemporaneidade e a Educação Física tem um papel fundamental no contexto desse desafio. Tudo isso, testemunha que o corpo tornou-se, uma referência central, dotado de uma relevância social, suscitando investigações sobre esse fenômeno que, especificadamente, também é objeto de estudo da Educação Física. Mas, quais seriam seus significados sociais?

\section{Significando o Corpo na História}

\footnotetext{
${ }^{1}$ Jocimar Daólio, atua na área de Educação Física Escolar e é responsável por embasamentos teóricos sobre a "Abordagem Plural da Educação Física", que tem esses elementos como pressupostos.
} 
A princípio, enquanto objeto de estudo de vários campos disciplinares, como a biologia, a medicina, a fisioterapia e a Educação Física, o corpo assumiu uma conotação de organismo vivo. Entendido como uma célula autônoma ou por várias células que funcionam de modo integrado, sugeriu-se com isso a harmonia entre órgãos no desempenho de suas funções. Essa é uma definição advinda do funcionalismo de Durkheim $^{2}$, que vê o corpo de forma biológica, tendo como conseqüência o seu aprisionamento na organicidade, sendo, portanto, apenas um fator individualizador, segundo a função social assumida por seu "dono". O corpo constituiria, nessa perspectiva, um "fato social" que pode ser concebido como uma "coisa" viva ou, simplesmente, uma "coisa".

Mas, essa definição puramente biologista de corpo, remanescente do final do século XVIII e inicio do século XIX, que nasce junto com as ciências sociais, mostrouse insuficiente, isto é limitada, para explicá-lo em toda a sua complexidade, pois tanto poderia expressar a definição de um animal qualquer ou de um ser humano. Assim, o corpo não se constituiria, somente em uma coleção de órgãos arranjados segundo as leis da fisiologia e da anatomia; mas, antes, em uma estrutura simbólica, superfície de projeções, possível de unir as mais variadas formas culturais.

Sabe-se, no entanto, que nem sempre foi assim. O corpo na idade média era percebido como centro dos acontecimentos, tendo uma idolatria divina sobre ele e uma conseqüente separação do corpo (res) profano, e espírito-mente (cogito) sagrado, sendo aqui definido como um instrumento de consolidação das relações sociais, e o poder das características físicas como: altura, cor da pele, entre outros, associadas ao vínculo que o indivíduo mantinha com o feudo, eram determinantes na distribuição das funções sociais. A moral cristã tolhia qualquer tipo de prática corporal que visasse o culto ao corpo, pois o mesmo poderia tornar a alma, sagrada, em impura.

${ }^{2}$ Émile Durkheim (1858-1917), principal representante do Funcionalismo (funções desempenhadas pelas pessoas para harmonia social), no qual a existência de uma consciência coletiva seria formada pela socialização do ser humano nessa sociedade. É considerado pai da Sociologia Moderna tendo fortes influências das Ciências Biológicas e do método cientifico. Concretizou que os verdadeiros objetos de estudo da sociologia eram os "fatos sociais". 
$\mathrm{Na}$ Renascença, o significado passa a ter bases científicas, servindo de objeto de estudos e experiências, no qual a disciplina e o controle corporal eram preceitos básicos; todas as atividades físicas relacionadas ao corpo eram prescritas por um sistema de regras rígidas, visando à saúde corpórea. Com isso, o dualismo que opõe o corpo e o espírito descrito primeiramente por Platão, que afirmava ser o corpo o cárcere da alma, e vivido por Descartes na forma cartesiana, que constituía o homem em duas substâncias: uma pensante, a alma, razão de sua existência; e outra material, o corpo visto como objeto para carregar a alma pensante, passará a ser analisado de outra forma na contemporaneidade.

Já na idade moderna essa cisão corpo-mente tornou-se possível com fundamento no desmantelamento da estrutura feudal e, por conseguinte, com a desestruturação do poder da igreja católica, proporcionando uma reorientação na forma de pensar o homem e sua relação com o corpo. "Os anatomistas antes de Descartes e da filosofia mecanicista fundam um dualismo que é central na modernidade e não apenas na medicina; aquele que distingue, por um lado, o homem, por outro seu corpo" (BRETON, 2003, p. 18).

Esta visão moderna trás em si um modelo de corpo-máquina, socialmente oprimido e manipulável, visto sob o prisma do ganho econômico a qualquer custo. Também, não se pode abstrair desse modelo, o local exercido pelo poder disciplinar, nos termos das sujeições descritas por Foucault (1986). Ainda como decorrência, a exploração recaía, também, sobre o corpo de quem trabalha, no intuito de maximizar a utilização da força de trabalho. Sem dúvida, está implícita uma prática domesticadora que impossibilitava a corporeidade do trabalhador.

No entender de Habermas (1987), esta dualidade e a maneira encontrada pelo homem para lidar com os problemas gerados pela modernidade, produziram quadros patológicos na sociedade determinando crises de direção e até mesmo diminuição na integração societária. Essas crises de direção podem ser compreendidas no sentido da teoria Weberiana como o desencantamento do sujeito no quadro moderno; a vida para o homem aparece sem sentido em função de sua descrença, especialmente, com a vida mundana. 
A apropriação e aplicação desses conceitos são percebidas dentro da história moderna e de acordo com Foucault:

[...] o controle da sociedade sobre os indivíduos não opera
simplesmente pela consciência ou pela ideologia, mais
começa no corpo e com o corpo. Foi no biológico,
no somático, no corporal que antes de tudo, investiu a
sociedade capitalista. O corpo é uma realidade bio-
politica. (FOUCAULT, 1986, p. 80 ).

$\mathrm{Na}$ dinâmica desse processo e com o advento do modelo socioeconômico capitalista, infere-se da obra Foucaultiana que a sociedade necessita de corpos fortes, saudáveis e homogêneos para atender a lógica de mercado e rotinas desumanas de trabalho em busca da alta produtividade e do lucro. Uma vez que seriam utilizados, transformados e aperfeiçoados para atender o capitalismo e estando, assim, sujeitos às técnicas de disciplinamento.

Mauss (2003), por sua vez, ao apresentar a noção de técnica corporal consegue situar o diálogo entre diferentes campos disciplinares, especialmente o das ciências sociais e o da Educação Física, extrapolando a visão funcionalista e fragmentada de corpo, definindo-o como o primeiro e mais natural instrumento do homem. As técnicas corporais se definiriam como: "as maneiras pelas quais os homens de sociedade em sociedade, de uma forma tradicional, sabem servir-se de seu corpo" (MAUSS, 2003, p. 401).

O referido autor, considerando o homem como ser total, isto é, na constituição humana os aspectos biológicos, psicológicos e sociais se fazem presentes, promove uma ruptura nas definições preponderantes no campo das ciências sociais e da saúde que pretendiam, durante o século XIX, tratar o homem apenas sob o prisma social; compreendendo a dimensão humana partir do pressuposto de que o homem constitui um "fato social total". 3

\footnotetext{
${ }^{3}$ Marcel Mauss (1872-1950), sociólogo e antropólogo francês, sobrinho de Émile Durkheim e é por ele influenciado. $\mathrm{O}$ "fato social total" foi concebido por Mauss em "O ensaio sobre a dádiva" (1924) para designar fenômenos sociais complexos que abrangeriam interpretações provenientes de diversas áreas do conhecimento, interdisciplinarmente.
} 
Agora, um dualismo contemporâneo apresenta-se separando o homem de seu próprio corpo que é transformado em um objeto a ser moldado e modificado, conforme o gosto do dia. Desse modo, equivale-se ao homem no sentido em que se modificando as aparências o próprio homem é modificado, em razão das exigências nos diversos setores da vida (escola, trabalho, esporte, etc.) Essa insuficiência em relação ao corpo é o que tem levado o ser humano a buscar estratégias para modificá-lo constantemente.

Diante do exposto, qual seria, então, o conceito de corpo na contemporaneidade? A considerar o contexto atual, a complexidade da sociedade e das suas relações, pode-se dizer que seria o de um corpo frágil, com limitações e em busca constante da perfeição; visto como um elemento que interrompe, que marca os limites da pessoa, local onde começa e acaba a presença do individuo, e que sofre influência inegável da sociedade; uma condição material da existência da vida no mundo. Em face a tais características, sugere-se, por assim dizer, a existência de uma valoração da aparência desse corpo no social. Mas, como se opera esse valor na sociedade nos dias atuais?

\section{A Valoração da Aparência Corporal Hoje}

A aparência corporal responde a uma ação do ator relacionada com o modo de se apresentar socialmente e de se representar quotidianamente. Engloba a maneira de se vestir, de se pentear e ajeitar o rosto, de cuidar do corpo, etc. que muda conforme as circunstâncias e de acordo como o estilo da presença do individuo. Segundo Breton ${ }^{4}$ (2006), o primeiro constituinte da aparência tem relação com as modalidades simbólicas de organização sob a égide do pertencimento social e cultural do ator. Elas seriam provisórias e amplamente dependentes dos efeitos da moda. Por outro lado o segundo constituinte diz respeito ao aspecto físico do ator sobre o qual dispõe de pequena margem de manobra: altura, cor da pele, etc.

Os traços dispersos da aparência podem facilmente se metamorfosear em vários indícios, dispostos com o propósito de orientar o olhar do outro ou para ser classificado

${ }^{4}$ David Le Breton (1953), sociólogo e antropólogo considerado uma importante referência para os estudos sobre o corpo, é professor da Universidade de Estrasburgo II na França. 
à revelia numa categoria moral ou social particular que, posteriormente se transformará em engajamento social.

A apresentação física de si passa a valer socialmente como se fosse a apresentação moral: pessoas de traços fisionômicos finos, brancas e bem vestidas são vistas como de "boa índole", angelicais e a elas não seria atribuído nenhum tipo de preconceito ou crime, pois a composição de sua aparência aproxima-se do ideal produzido ideologicamente, e as de traços contrários a esse modelo estabelecido socialmente, seriam vistas como de "má índole".

A cultura, contudo, ao marginalizar os que se encontram na "diferença" tendenciona as pessoas a buscarem uma aparência que as torne muito parecidas entre si. Essa semelhança não significa igualdade. Pelo contrário, imputa ao ostracismo àqueles que, as qualidades despertam vergonha e assim, são negadas, escondidas e camufladas, principalmente pelos negros que se sentem distantes desse modelo, e para tal proximidade muitas vezes renegam sua etnia. Assim, moldam-se os corpos de forma que a peça no "quebra-cabeça social" se encaixe perfeitamente, pois se forem diferentes não serviram adequadamente para a rede que constitui a sociedade.

Breton (2006) expõe que a ação da imagem coloca o ator sob olhar apreciativo do outro e, principalmente o coloca na tabela do preconceito que o fixa de antemão numa categoria social ou moral conforme o aspecto ou detalhe da vestimenta e conforme a forma do rosto ou do corpo. Os estereótipos se fixam com predileção sobre as aparências físicas e as transformam naturalmente em estigmas, em marcas fatais de imperfeição moral ou de pertencimento a determinado grupo social.

O corpo torna-se, sob esse prisma, um acessório, um objeto imperfeito, um rascunho a ser corrigido; trata-se de fato de mudar o corpo para mudar a vida, pois o corpo exaltado não é o mesmo com o qual vivemos, mas um retificado, redefinido para atender padrões sociais estabelecidos como ideais.

Esse caráter disponível e provisório do corpo sutilmente separado de si, mas colocado como o caminho propicio para fabricar uma presença à altura da vontade do domínio dos seus atores, faz da anatomia não mais um destino mais um acessório da presença, uma matéria-prima a modelar, redefinir e submeter ao design do momento. O corpo não é, mais apenas, nas sociedades contemporâneas, a determinação de uma 
identidade intangível, a encarnação irredutível do sujeito, mas uma construção, uma instância de conexão, um objeto transitório e manipulável suscetível a muitos emparelhamentos.

Dentro desse cenário, a chamada indústria cultural, de acordo com Detrez (2002), exerce forte poder sobre o corpo humano e o influencia, com uma exposição de exemplos magros e malhados idealizando estereótipos invejáveis, e citando o filme "Sherek" a autora mostra que há possibilidades de fuga desse contexto, pois ao expor um personagem protagonista de aparência feia, fez o telespectador refletir que não precisamos de transmutações para agradar os olhos alheios, onde o que vale é o caráter moral, estar bem consigo mesmo e não ser uma figura linda visualmente, exemplo este que é exceção diante da galeria de filmes comerciais que ditam padrões de beleza.

Para melhor se expor ao mundo, são usados todos os meios possíveis: os hormônios ou a dietética aumentam a massa muscular, os regimes alimentares mantém a silhueta, os piercing ou as tatuagens dispensam os sinais de identidade sobre a pele ou dentro dela, ou seja, o individuo tenta reivindicar o remanejamento de seu corpo à vontade e também de revelar modos inéditos de criação. Existem alguns que sonham em até agir diretamente sobre a fórmula genética do sujeito para modelar a forma de seus futuros descendentes e diminuir as remodelagens futuras. Todas essas condutas isolam o corpo como uma matéria à parte que fornece um estado do sujeito. "Ser o que se é torna-se uma performance efêmera, sem futuro, um maneirismo desencantado em um mundo sem maneiras" (BAUDRILLARD, 1997, p. 22 apud BRETON, 2003, p. 29).

A cirurgia estética, dentro desse contexto, passa por um desenvolvimento considerável, aumentado por esse sentimento de maleabilidade do corpo. Sua transformação em objeto a ser modelado traduz-se de imediato nos catálogos que os cirurgiões depõem nas salas de espera e que mostram aos clientes para, assim, propor uma intervenção precisa: seios modificados por próteses ou remodelados, vários tipos de liftings, lábios reconstruídos por injeções, lipoaspirações ou retalhamento da barriga ou das coxas, implantes subcutâneos, tudo para induzir as proporções físicas desejadas.

A saúde fica, muitas vezes, em segundo plano e os riscos de vida nessas intervenções passam desapercebidos, pois o principal objetivo é atender a 
"necessidade" do momento, no qual a vontade de modificar os olhares sobre si miniminizam os medos, principalmente o de morte, no qual segundo Breton (2002) a cirurgia estética não é uma metamorfose banal de uma característica física ela opera, em primeiro lugar, no imaginário e exerce uma incidência na relação do individuo com o mundo.

Dispensando um corpo antigo e mal amado, a pessoa goza antecipadamente de um novo nascimento, de um novo estado civil e a cirurgia estética oferece um exemplo impressionante de consideração social do corpo como artefato da presença e vetor de uma identidade ostentada. É um corpo que passa a ser fabricado e incorpora-se isso como valor, onde geralmente quem não se adapta é colocado à margem da sociedade, sendo quase afastados do convívio social por serem diferentes, é o caso, por exemplo, dos adeptos ao body $\operatorname{art}^{5}$.

A apresentação da pessoa para o mundo estaria, então, condicionada a fatores alheios de sua vontade, estabelecidos social e culturalmente e que a influencia de tal maneira que dita seu modo de ser e agir no ambiente em que está inserido; e um dos mecanismos ideológicos de apoderamento e aprisionamento do corpo coletivamente é a mídia.

\section{Os Usos do Corpo pela Mídia}

O discurso midiático e os interesses mercadológicos por modelos de corpos ideais, para venderem seus produtos e sua ideologia que é dominante, crescem constantemente, e o poder que gira em torno deste imaginário faz das pessoas reféns, até certo ponto, dessa ótica corpórea estereotipada. A mídia contemporânea vincula, na maioria das vezes, corpos que se encaixam em um padrão estético "aceitável", mediados pelos interesses da indústria de consumo, utilizando um jogo de imagens para seduzir os indivíduos e transformá-los em potenciais consumidores de seus modelos de beleza e estética.

\footnotetext{
${ }^{5}$ Corpo arte transformado em objeto, simples acessório da presença, como forma de contestação contra a efemeridade do momento, tendo-o como lugar onde o mundo é questionado.
} 
Segundo Detrez (2002), ao criarem essas associações entre corpo ideal e o sucesso, constroem-se a imagem do belo, formando o corpo conforme os saberes e os valores de uma sociedade que o idolatra como uma forma de manipulação das massas, tornando-o em um instrumento de poder a serviço da dominação social, política e econômica; não se importando com as condições econômicas da maioria das pessoas que são atingidos por seus veículos, pois o importante é impor seus ideais e que cada um faça o impossível para adequar-se e atender a seus ditames e ser, assim, aceito no grupo ao qual pertence; criando desse modo, nessas pessoas, um mecanismo de fuga da realidade e de compensação diante da frustração e impotência cotidiana provocada pelas diferenças sociais.

Trata-se, portanto de descobrir que corpo para qual sociedade, ou ainda, que corpo por qual sociedade.

O corpo passa, portanto, a ser condição material da existência da vida no mundo, desse modo à propaganda apodera-se da subjetividade de cada individuo incitando-o a recriar-se segundo o modo ou estilo de vida que ele propaga e de acordo com Guatari, 1992, p. 14

As máquinas tecnológicas de informação e de comunicação operam, no núcleo da subjetividade humana, não apenas no seio da suas memórias, de sua inteligência, mas também de sua sensibilidade, dos seus afetos, de seus fantasmas inconscientes

Breton (2002) afirma que esses valores de mercado que regem a vida da maioria das pessoas são buscados devido à fragilidade e vulnerabilidade do corpo, principalmente à doença e a velhice que são intoleráveis em sociedades competitivocapitalistas. Essa exaltação do corpo "coisificado" é um fantasma irrisório de quem abandona toda soberania sobre sua existência para entregar-se às técnicas contemporâneas de eterna juventude, mas claramente evidencia-se que essas representações sociais e culturais que orientam os usos da corporeidade mudam socialmente, pois o corpo recebe reflexos dessa sociedade e por isso o transforma e o reconstrói, levando os indivíduos a terem uma visão fragmentada do próprio corpo. 
A mídia, conforme DaMatta ${ }^{6}$ (1985) é o meio pelo qual o produto, produzido desumanamente no sistema capitalista, pode ser inserido na rede das relações sociais para o qual se destina, e para esse objetivo a mídia utiliza-se do corpo. Em inúmeras propagandas, os produtos aparecem associados a um corpo saudável, sensual, onde o objetivo é ligá-lo a um momento de prazer, usando-o com a intenção implícita de fazer associação desse produto industrial com vivencias de um estilo de vida idealizado, com intensa participação corporal, de criatividade e liberdade, aspectos que estão distantes das reais vivencias de corporeidade que participaram de sua produção.

Esse fenômeno, resgatado por DaMatta, oculta em sua manifestação uma carência, do homem contemporâneo, de momentos em que ele participe como unidade existencial, de corpo e espírito, numa relação próxima de si com seu corpo numa tentativa de humanizar a produção, relacionando-a com um corpo vivo e participante, que se pretende distante da dicotomização corpo-espírito inerente ao sistema de produção capitalista.

A mídia televisiva, por sua vez, que está disponível a maioria da população é responsável pela veiculação de imagens e informações que levam a população a criar a ilusão que podem realizar escolhas autenticas, mas de fato todas as escolhas já estão previstas e feitas facilitando, assim, a aceitação de valores oferecidos pelo discurso midiático, difícultando a possibilidade de construção de outros enunciados sobre eles.

Assim, a mídia, ao mesmo tempo em que permite a expansão desse sistema de produção, incentivando o consumo que exige um arquétipo de homem que se adeqüe as exigências da sociedade dominante, consagra sua permanência, criando o mito de uma sociedade humana. A mídia, de acordo com o exposto, usa o corpo para estabelecer padrões alienantes, criando um ideário de corpo como objeto de desejo e consumo.

\section{O Papel Reflexivo da Educação Física: Significar e Re-significar o Corpo na Prática Escolar}

\footnotetext{
${ }^{6}$ Roberto DaMatta (1940) Doutor em Antropologia pela Harvard University, realiza pesquisas em etnologia indígena brasileira e escreveu livros sobre a cultura indígena.
} 
Antes de caracterizar aqui o papel da Educação Física, verificar-se-á, brevemente, o papel da escola no processo de construção da noção de corpo pelos alunos, à medida que a escola constitui uma instituição social que se encontra numa relação dialética com a sociedade onde se insere. Desse modo, ao mesmo tempo em que se reproduzem às estruturas de dominação existentes na sociedade, a escola constitui-se em um espaço onde se pode lutar pelas transformações sociais. Considerando essas estruturas e a possibilidade de transformá-las, os significados conferidos podem, portanto, ser re-significados nos contextos das práticas escolares.

A forma de a escola controlar e disciplinar o corpo estão ligados aos mecanismos das estruturas de poder resultantes do processo histórico da civilização ocidental, no qual as práticas escolares tendem a perpetuar a forma de internalização das relações do homem com o mundo, que consiste na supervalorização das operações cognitivas e no distanciamento do corpo; pretendendo não somente discipliná-lo mais obscurecer seus sentimentos, idéias, lembranças e até mesmo anulá-lo. Acredita-se que seriam esses os significados tradicionais que freqüentemente são atribuídos e incorporados pela escola, em sua dinâmica, ao corpo.

Foucault (1986), em seus estudos relata como se efetiva o poder disciplinar sobre o corpo nas escolas, onde nos séculos XVIII e XIX eram tidas como fábricas que reproduziam disposições para ações racionais voluntárias, ao mesmo tempo em que procuravam eliminar dos corpos, movimentos involuntários. A rigorosa minúcia com que eram estipulados os regulamentos para o comportamento corporal dos alunos para sua distribuição no espaço e para a divisão do tempo escolar revela um poder disciplinar que objetiva controlar as erupções afetivas que poderiam surgir do corpo com seus movimentos espontâneos, com isso os movimentos corporais tornavam-se dissociados das emoções momentâneas, perpetuando controle e manipulação. A partir dos anos 60 percebeu-se que esse poder não era assim tão indispensável quanto se acreditava, podendo, então, ser imposto um poder mais tênue sobre o corpo.

Porém, não é isso que constatamos em nossas escolas; o que vemos é que esse poder descrito por Foucault é vivo e atuante na realidade escolar e que não foi atenuado na maioria dos casos; vemos corpos disciplinados rigidamente por professores, que independente de sua área de estudo, primam por comportamentos mecânicos e 
homogêneos dentro de um padrão alienante em que a quietude é vista como condição sine qua non para o aprendizado eficaz e dessa forma conduzem seus alunos a uma vida social submissa e com valores pré-estabelecidos como adequados. Com base nesses pressupostos teóricos, a prática disciplinar pode ser considerada como um significado central na dinâmica de funcionamento da escola.

Segundo Maria Augusta S. Gonçalves (1994) a aprendizagem dos conteúdos é uma aprendizagem sem corpo, e não somente pela exigência de o aluno ficar sem movimentar-se em cadeiras enfileiradas, mas sobre tudo pelas características dos conteúdos e dos métodos de ensino que o colocam em um mundo diferente daquele no qual ele vive e pensa com seu corpo, sendo que o conhecimento é feito de forma fragmentada, abstrata e sem significação para o aluno.

Chegamos à Educação Física, que acredita-se ter o corpo como seu objeto de estudo e que deve constituir-se em um fator pedagógico que vise à libertação integral do homem e à recuperação de sua dignidade corporal, buscando a autonomia de movimentos corporais.

Recorrendo às contribuições teóricas do filósofo Merleau-Ponty (1980), entende-se que a Educação Física na escola deve possibilitar aos alunos uma outra visão do corpo, fundada na totalidade humana. Desse modo, os movimentos devem estar integrados a essa totalidade, para a busca da concretude corporal. Isso implica, necessariamente, compreender o homem de forma integral.

A Educação Física escolar deveria constituir-se, portanto, em um espaço para oportunizar aos alunos à compreensão, à crítica e o questionamento desse momento de idolatria à imagem narcísea do corpo, que é veiculada socialmente. Estaria nessa abertura, a condição de possibilidade de re-significação do corpo, com vistas à conscientização da relevância da prática da Educação Física na escola, como uma atividade necessária à própria condição humana, instrumentalizando, assim, os alunos para que possam optar pelo tipo de corpo que querem "carregar" socialmente.

Em que pese a dificuldade de compreender e explicar a transmissão ideológica do sistema dominante do ideal de corpo como uma estratégia reprodutora, alienante e castradora do ser humano no contexto da prática; a re-significação deveria ser realizada nas aulas, a partir de discussões sobre o que fazer em termos de atividade: prática de 
esportes, recreação, aulas teóricas, festivais de jogos, atividades junto às comunidades, etc.

Caberia ao professor, a responsabilização por esse processo de conscientização junto aos seus alunos nas práticas pedagógicas. A compreensão e o conhecimento do professor acerca do paradigma do alto rendimento, da veiculação pela televisão e os demais meios de comunicação, do padrão de corpo imposto pela sociedade, dos mecanismos de opressão, violência e estresse diário dos corpos dos trabalhadores, da ditadura do consumo de alimentos agressivos ao corpo e o tratamento mercadológico do mesmo, na moda e no esporte da alta competição; são horizontes de conhecimento que não podem ser perdidos de vista. Afinal, esses usos e malefícios que acometem o corpo, reforçam o fato de que este é uma construção social e cultural resultante de um processo histórico que precisa ser considerado e bem fundamentado pelos professores.

A Educação Física Escolar, portanto, não pode ignorar as relações do homem com seu corpo e com a saúde do mesmo, no contexto geral onde o homem se insere como um todo, para estar apta a desmistificar, nas práticas vigentes, seu conteúdo ideológico, alienante e contrário aos valores educacionais maiores. Desse modo, a oportunidade e diversidade de escolhas, permitiriam ao aluno pensar e repensar os padrões e modelos impostos pela sociedade e que estão impregnados no "fazer" Educação Física na escola.

Nesta perspectiva, Arroyo (2000, p. 72), em seus estudos sobre educação e teoria pedagógica, afirma que dar ao corpo centralidade no processo educativo é uma tarefa fundamental da escola e principalmente dos professores de Educação Física e os desafia a buscarem estratégias para recuperar a corporeidade como elemento de formação humana:

A educação dos corpos - e não seu adestramento e controle -
merece maior atenção nos processos escolares. É uma das
lacunas mais lamentáveis em nossa pedagogia. Recolocar o
corpo na centralidade que ele tem na construção de nossa
identidade e da totalidade da nossa cultura exige criatividade
profissional de todos.

A Educação Física na escola confere, hoje, significados contemporâneos ao corpo, como os citados no decorrer do artigo, devido a influências inavegáveis, 
especialmente, da sociedade no ambiente escolar, cabe, então, aos professores em suas práticas pedagógicas construir um novo significado ao corpo, através da conscientização crítica de seus alunos para uma posterior emancipação; transformando, assim, o corpo de objeto social para sujeito.

Não há, portanto, uma cultura de movimento, mas culturas de movimentos que estão presentes nas experiências dos educandos. Acredita-se que as condições de possibilidade de re-significação dos valores, está justamente na mediação entre os conhecimentos culturais e os da escola, a que deve ser feita pelo professor num clima emancipatório.

\section{Considerações Finais}

No presente artigo buscou-se promover reflexões acerca do corpo, enquanto construção social e histórica, no contexto da prática da Educação Física na escola. A partir das premissas relativas aos significados do corpo ao longo da história humana, a constituição das aparências corporais e as conseqüências dessa busca incessante pelo corpo ideal, além das imposições sociais e culturais, percebe-se a relevância de debater esse tema. Aliás, a temática do corpo sempre esteve na ordem do dia, não apenas nos discursos, mas nas práticas sociais cotidianas, dentre as quais a da Educação Física Escolar.

A partir da fundamentação teórica, construíu-se uma base para reflexões e argumentações. Por meio do que foi exposto, fica evidente a fragilidade do corpo, suas limitações e o que leva as pessoas a buscarem algo mais, como se fosse uma necessidade de superação.

Como na história, o desprezo pelo corpo é uma forma de desprezar a si mesmo, o que não é verdadeiro para a maioria das sociedades humanas, tanto que em algumas as transformações do corpo realçam uma dimensão lúdica ou uma construção de si próprio. A corporeidade hoje passa a ser determinada por fatores extrínsecos a vontade do individuo. E ao alcance das mãos, de certa forma, o individuo descobre através do corpo uma forma possível de transcendência pessoal e de contato. O corpo não é apenas uma máquina inerte, mas um alter ego de onde emanam sensações e sedução. Ele se 
transforma no lugar geométrico da reconquista de si, um território a ser explorado na procura de sensações inéditas a serem capturadas.

O perigoso discurso midiático que nos é imposto, apresentado pela figura do ídolo a ser copiado, também, merece atenção, pois a cultura narcísica mostra pressupostos de beleza física constantemente valorizada e colocada como padrão estético, tornando o corpo descartável.

Mas há como fugir desse determinismo e não acatar o que efêmero, descobrindo o quê o corpo sente e usando essas influências sociais e culturais para saber o tipo e estilo de corpo que queremos, tendo criticidade para analisar tudo que nos é imposto, e a partir das identificações feitas, criarmos nossa própria identidade corporal num processo de individuação (relativo ao sujeito/individual), sem ser "abusado" pelo ambiente social, ou seja, questionar os valores pré-estabelecidos, como corretos, e poder tomar decisões. A reflexão aqui proposta evidencia, então, a necessidade da criação de formas de reação e contestação aos novos modos de controle corporal estabelecidos pela contemporaneidade.

Por fim, a Educação Física tem um papel primordial na busca por concepções que visem à emancipação corporal e sua re-significação, intermediados por um discurso crítico da realidade em que o indivíduo está inserido, não se portando como mera reprodutora, para que mudanças efetivas nos atuais paradigmas que norteiam o corpo possam ser concretizadas e assim combater os mecanismos de reprodução dos padrões estéticos referidos e conferir novas formas de interação entre o homem e seu corpo. E a escola é o meio propicio para a emancipação, pois somente uma contrapressão poderá exercer um papel decisivo para a libertação de um corpo que passará a absorver as ameaças e delas extrair o alimento de sua renovação. Um corpo que não admita maniqueísmos. Pois será a partir de embates críticos, estimulados durante a intervenção pedagógica do professor (contextualizadas social e culturalmente), que conseguiremos conceber uma educação física que trabalhe com corpos, e acima de tudo com sujeitos, donos desses corpos.

Residindo aqui, ainda, a importância de se trazer pontos de vista diferentes, como alguns que embasam a Sociologia do Corpo, descritos brevemente nesse artigo, 
de modo a iluminar a compreensão em torno deste, que é a essência de nossa área, o corpo.

O corpo, então, desvenda um campo infinito de possíveis pesquisas e a esse respeito, o homem só será "libertado" quando qualquer preocupação com o corpo estiver desaparecida. E isso algum dia acontecerá?

\begin{abstract}
This article, of interpretative background, aims at presenting a reflection on the role of physical education at school in redefining the student's body, in face of the ideal body stereotype, which has been constructed in nowadays. The article turns to the contributions of a few scholars who focus on studying the body, mainly Le Breton, and to the ideas of social scientists, such as, Durkheim and Foucault; anthropologist Mauss. The article reflexively approaches the issue of the body in "doing" physical education, in which the teacher and the students unite the conditions and possibilities of the body's redefinition through consciousness, overcoming the fragmentation of the body and proposing an interdisciplinary constitution. This reflection requires, therefore, the recognition of the reality of the pedagogical practice of physical education at school, as an emancipatory social space and not only a mere reproductor of traditional practices.

Key-Words: Body, Contemporary society, Redefinition, Media; Physical Education at school.
\end{abstract}

\title{
Referências Bibliográficas
}

ARROYO, M. Oficio de mestre: imagens e auto-imagens. Petrópolis: Vozes, 2000.

AZEVEDO, A. O poder na escola: um estudo da prática disciplinar na Educação Física. 1993. Dissertação (Mestrado em Educação Brasileira) - Universidade de Brasília, Brasília, 1993.

DAMATTA, R. Vendendo totens: prefácio prazeroso para Everardo Rocha. São Paulo: Brasiliense, 1985.

DAÓLIO, J. Da cultura do corpo. Campinas: Papirus, 2005.

DETREZ, C. La construction solicale du corps. Paris: Èditions du Senil, 2002.

DURKHEIM, É. Da divisão do trabalho social. São Paulo: Martins Fontes, 1995.

FOUCAULT, M. Microfisica do poder. Rio de Janeiro: Graal, 1986. 
GONÇALVES, M. A. S. Pensar, agir: corporeidade e educação. Campinas: Papirus, 1994.

HABERMAS, J. The theory of commuicative action. Boston: Potity, 1987.

KUNZ, E. Educação Física: ensino e mudanças. Ijuí : Unijuí, 2001.

LE, B. D. Adeus ao corpo: antropologia e sociedade. Campinas: Papirus, 2003.

A construção social do corpo. Campinas: Papirus, 2002.

. A sociologia do corpo. Petrópolis: Vozes, 2006.

MAUSS, M. Sociologia e antropologia. São Paulo: Casac \& Naify, 2003.

MEDINA, J. P. A Educação Física cuida do corpo e... "mente”. Campinas: Papirus, 1987.

MERLEAU, P. M. Fenomenologia da percepção. Rio de Janeiro: Freitas Barros, 1980. 